\title{
A COMPARISON BETWEEN EXPERIENTIAL AND ECMWF REANALYZED CONDENSED MOISTURE PROFILE OVER THE NORTHEASTERN SPHERE
}

\author{
Xuezhong Wang ${ }^{1, *}$, Banghui Hu ${ }^{1}$, Ju Wang ${ }^{1}$, Hong Huang ${ }^{1}$, Wenjing Zhang ${ }^{1}$, Fukai Lin ${ }^{2}$ \\ ${ }^{1}$ School of Meteorology and Oceanography, National University of Defense Technology, Nanjing, China - (wxzplaust@163.com, \\ hubanghui@126.com, wangjqy@vip.sina.com, hhong7782@sina.com, zhangwj-lgd@sohu.com) \\ ${ }^{2}$ Unit 31700, PLA, Liaoyang, China - linfukai_ly@163.com
}

Commission III, WG III/8

KEY WORDS: Condensed Moisture, Experiential Profile, Warm Cloud, Liquid Water Path

\begin{abstract}
:
Base on January and July 4-times daily ECMWF Interim data from 2009 to 2018 over the Northeast Sphere (0-180E,0-90N), the condensed moisture profile of experiential methods and that of ECMWF analysis are compared. The result shows that, the meridional-height distribution of mean cloud condensed moisture has a maximum slab spreading near ground in the Arctic region in July, and the maximum takes a circular shape at $700 \mathrm{hPa}$ above $30 \mathrm{~N}$ latitude in January. The distribution feature unlike the universal profile, it distributes in a single or double peak function manner, instead of a constant value. The quick decreasing level height and thickness varies with latitude, especially in January. The second experiential profile concerning warm cloud assumes air parcel lifting adiabatically, the liquid water path (LWP) is compared for general information. The result shows that the experiential LWP is much larger than that of the reanalysis by 1 to 2 order, decreasing with latitudes. The possible reason of LWP difference is from the critic water content value of cloud boundary identification. If the value is small, the thickness of warm cloud will be large, temperature and pressure at the cloud base are both large too, results in a larger LWP. These results will enrich the knowledge of the condensed moisture characteristics of ECMWF reanalysis and the experiential moisture profile methods.
\end{abstract}

\section{INTRODUCTION}

\subsection{The Importance of Cloud}

Cloud is very important in the view of climatology and synoptics. It badly influences the radiation transport in the atmosphere (Niu et al. 2008), thus it is a key factor for global energy and water circulation. It an important observing item at meteorological observatory. It is visible of moisture concentration and transport. It obstacles the aerial visibility, the cloud changes the air plane aerodynamic structure by icing, and damages the engine of the aircraft by the hail parcels, the cloud seriously influences the civil or military aviation.

\subsection{The Description Cloud}

In physics, the cloud is described through certain ways. The first, relative humidity (Slingo, 1980; Wang and Rossow, 1995), when the relative humidity of air parcel greater than a critic value, the air parcel is classified to cloud, and vice versa, the cloud top and base are also identified by critic relative humidity. The second, dew point depression (Poore et al., 1995), it is another variable describes the vapour content in the air parcel. Different from the relative humidity, the less is the dew point depression, the wetter is the air parcel. The third, the vertical second order differential of air temperature and relative humidity (Chernykh and Eskridge, 2010), the cloud is identified at the overlap section of the air temperature differential greater than 0 , and the relative humidity differential less than 0 . The last, condensed moisture, it is not a conventional observable variable, in most cases, it's a diagnostic or predictive variable in meteorology numerical models (Sundqvist, 1978) and often a general name of a set of variables including liquid water content, ice water content, snow water content and etc. The condensed moisture is used to judge the cloud existence by a critic value. The introduction of condensed moisture is one of the significant features of modern numerical atmospheric models.

\section{DATA AND METHODS}

\subsection{Data}

The data is ECMWF Interim data, the January and July 4 times daily from 2019 and 2018 are selected, the region covers 0$180 \mathrm{E}$ and $0-90 \mathrm{~N}$, with horizontal resolution is $1 \mathrm{x} 1$ degree and vertical 37 pressure layers. The variables include geopotential, temperature, relative humidity, fraction of cloud cover (FCC), specific cloud liquid water content and specific cloud ice water content.

\subsection{Methods}

Linear fitting and polynomial fitting. These methods are used to investigate the relations between two variables (dependent and independent variables), such as the column maximal FCC and the column maximal condensed moisture, the mean condensed moisture and its corresponding pressure.

Liquid water content experimental profile (Ackerman and Cox, 1987):

\footnotetext{
* Corresponding author
} 


$$
L W C=\left\{\begin{array}{lc}
10^{(p-750) / 320} & p<750 h P a \\
1.0 & p<750 h P a
\end{array}\right.
$$

Where $\quad p=$ air pressure, $\mathrm{hPa}$

$$
L W C=\text { liquid water content, } \mathrm{g} \mathrm{m}^{-3}
$$

In some research (Lee, 1999), the $L W C$ is regarded as the summation of liquid water content and ice water content, so hereafter the Eq.(1) defined profile is called universal profile.

Liquid water content of warm cloud. Air parcel is assumed lifting adiabatically. The vapour condensed and keep moving with the air parcel. The fitness profile is as following (Kosarev and Mazin, 1972, Tisler and Savijärvi, 2002)

$$
L W C_{a d}\left(T_{0}, P_{0}, z\right)=\left(a_{1}+a_{2} T_{0}\right) z+\left(a_{3}+a_{4} T_{0}+a_{5} T_{0}^{2}\right) z^{2}
$$

Where $\quad T_{0}=$ air temperature at cloud base, centigrade $P_{0}=$ air pressure at cloud base, $\mathrm{hPa}$

$z=$ height above cloud base, $\mathrm{km}$

$a_{i} i=1,5$ are parameters, the details may cite from Tisler and Savijärvi (2002)

\section{PATTERN OF CONDENSED MOISTURE}

\subsection{An Example Case}

First, column maximal value is defined as the maximal value of a variable of 37 layers at a grid point. Then the relation among the column maximal value of FCC, the condensed moisture (summation of specific liquid and ice water content), relative humidity are investigated. An example analysis at $0 \mathrm{Z} 1 \mathrm{Jul}$ 2019 shows that the column maximal FCC is significantly related to either the maximal condensed moisture or maximal relative humidity (Figures omitted). This indicates that why relative humidity or condensed moisture can be used as basis for cloud identification. The result also shows that the a large proportion of column maximal relative humidity exceeds $100 \%$, i.e. at the state of supper saturation of the ECMWF Interim relative humidity.

Then the coherence of FCC and the condensed moisture is investigated by example analysis. The longitude-vertical section along $100 \mathrm{E}$ at the aforementioned time is shown in Figure 1. The $0.001 \mathrm{~kg} \mathrm{~kg}^{-1}$ consists with the $0.01 \mathrm{FCC}$ well, and is selected as the critic value for cloud identification.

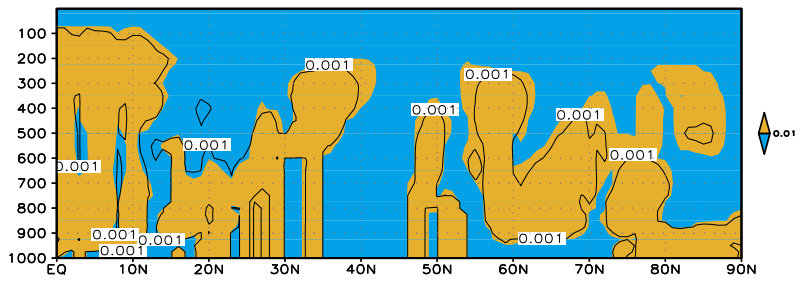

Figure 1. the longitude-vertical section along 100E of FCC (shaded, only 0.01 isoline is given) and condensed moisture (contour, only $0.001 \mathrm{~kg} \mathrm{~kg}^{-1}$ isoline is given).

\subsection{CT Analysis of Condensed Moisture}

The zonal or meridional mean condensed moisture of the ten years are analyzed with concept of computer tomography (CT). For the zonal (meridional) mean is computed and plotted every 10 longitude (latitude) degree bands. The result shows that the horizontal distribution of condensed moisture is highly dependent on the geography and atmospheric circulation (Figures omitted). The most outstanding feature is the maximum condensed moisture layer over the Arctic region in July and a maximal wet core downstream of the Tibet Plateau in January.

\subsection{Thermodynamic Phase of Condensed Moisture}

The distribution of supercooled water exists several opinions: some suggest its percentage decrease linearly from $100 \%$ to zero in the range of 0 to -40 centigrade, some claim linearly decrease but a narrow range 0 to -30 centigrade, the other believe nonlinearly and/or different width of ranges. The observed case are more complex (Zhao and Lei, 2014; and references therein). The zonal mean condensed moisture and specific cloud liquid water content are computed. And the ratio between mean specific cloud liquid water content and condensed moisture are plotted in Figure 2. The result shows the quick decreasing band is between 0 to -20 centigrade in general, either January or July.
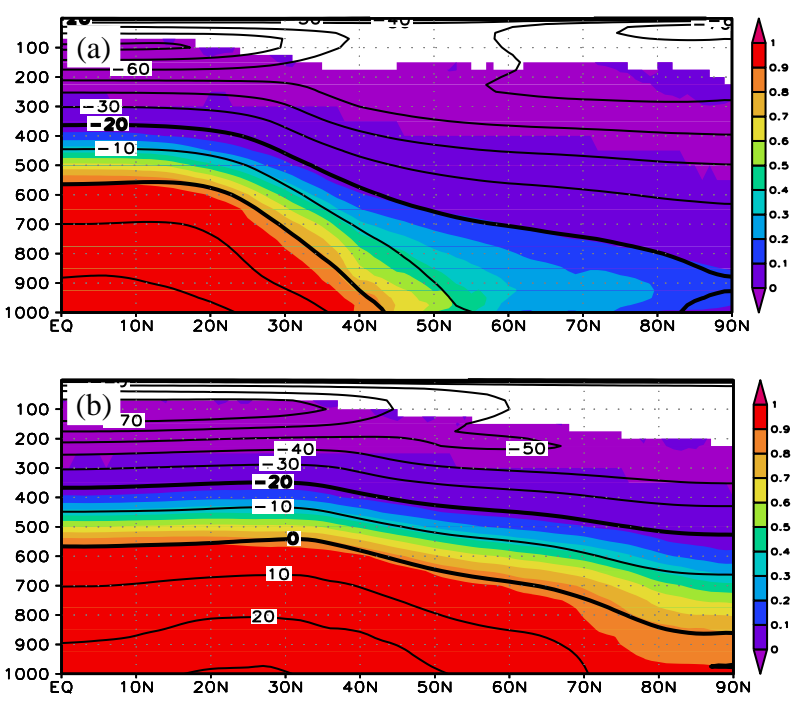

Figure 2. Ratio of zonal mean specific cloud water content and condensed moisture (shaded) and corresponding mean temperature (centigrade) in Jan. (a) and Jul. (b).

\subsection{Comparison with Universal Profile}

The zonal mean condensed moisture is compared with the universal profile. As defined in the equation, the cloud water content is constant below $750 \mathrm{hPa}$, and exponential decreasing to its $1 / 10$ after $320 \mathrm{hPa}$ 's lifting. The 10 year zonal mean cloud water content is neither constant in low levels, nor a constant pressure apart to decrease rapidly, i.e. the zonal mean reanalyzed profile is greatly different from the universal profile (Figure 3, shaded). With a maximum 5 order polynomial fitting (Figure 3, contour), the latitude dependent fitting accords well with the reanalysis profile, the best fitness order is 4 at middle and high latitudes. 


\section{DISCUSSION AND CONCLUSION}
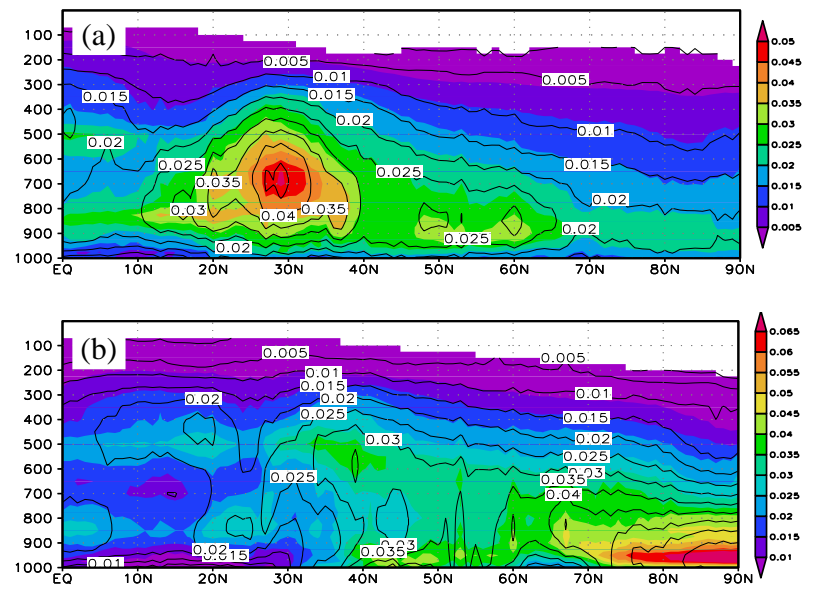

Figure 3. Zonal mean specific cloud water content (shaded) and its polynomial fitting (contour) in Jan (a) and July (b) $\left(\mathrm{kg} \mathrm{kg}^{-1}\right)$

\subsection{Comparison with Warm Cloud Profile}

How is a warm cloud defined? Using the critical condensed moisture, and the condensed moisture profile. The cloud base and top are identified, the corresponding environmental variables such as geopotential height, temperature are interpolated. The warm cloud is defined when its top temperature no less than 0 centigrade.

The liquid water path (LWP) is the vertical integration of liquid water content and can be regarded as the whole feature of the condensed moisture profile. The EC LWP is computed by the integration of condensed moisture between warm cloud base and top. The KM LWP is computed by the integration of the same vertical range with experimental equation (2) decided condensed moisture.

The ratio of EC and KM LWP is shown in Figure 4. The common pattern is that the ratio is less than 1.0, the ratio at high latitudes or over high topography tends to be larger. The smallest ratio region stands near the thermal tropic.
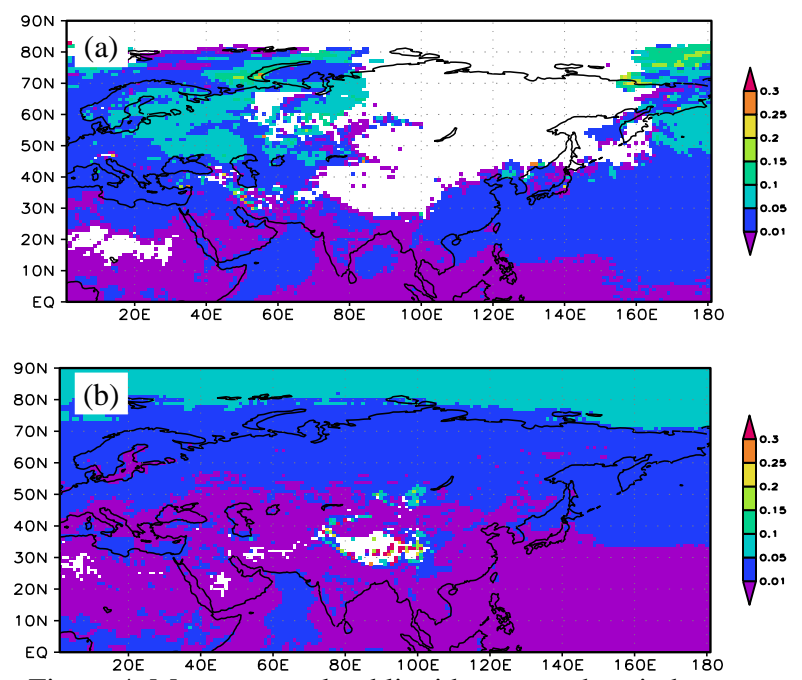

Figure 4. Mean warm cloud liquid water path ratio between reanalysis and warm cloud profile in Jan (a) and July (b).
The column maximal FCC is closely related to column maximal relative humidity and condensed moisture, this means that using relative humidity and condensed moisture critic value to identify cloud base and top is reasonable.

The zonal mean ratio of mean specific cloud water content decreases quickly between the temperature range 0 -20 centigrade. The range width is narrower than that of some research.

The column maximal condensed moisture is geography and atmospheric general circulation related. The maximal condensed moisture core downstream the Tibet Plateau in winter might result from the disturb by topography triggering the atmospheric wave and transports near surface vapor upward. The universal profile does not consist well with the zonal mean profile of the reanalysis data, while the multi-order polynomial fitting does. This indicates a geographical/temporal dependent experimental profile will much better than the independent one.

The LWP comparison of warm cloud shows that the KM warm cloud condensed moisture is possibly the upmost limitation of the reanalysis: for the cloud water may evaporate and diffuse, then the remainder less than the quantity of the background physical lifting process. The critic value of condensed moisture also play an important role, the larger is the critic value, the higher is the cloud base and thinner of cloud thickness, makes the smaller the KM LWP, and thus the ratio increases.

\section{ACKNOWLEDGEMENTS}

This research is supported by National Key R\&D Program of China with Grand No. 2018YFC1507604. The ERA Interim data are download from: http://apps.ecmwf.inc/datasets/

\section{REFERENCES}

Ackerman, S. A., and Cox, S. K., 1987. Radiactive energy budget estimates for the 1979 southwest summer monsoon. $J$. Atmos. Sci., 44, 3052-3078.

Chernykh, I. V., Eskridge, R. E., 2010. Determination of cloud amount and level from radiosonde soundings. Journal of Applied Meteorology, 35(8):1362-1369.

Kosarev, A. L., Mazin, I. P., 1972. A formula for computing the adiabatic value of cloud water content(in Russian). Sov. Meteorol. Hydrol., 3, 107-110.

Lee, H. S., 1999. Cloud specification and forecasts in the Florida State University global spectral model. A dissertation for the degree of doctor of Philosophy, The Florida State University College of Arts and Sciences. UMI microform 9955942. Bell \& Howell Information and Learning Company, $361 \mathrm{pp}$.

Niu, J., Carey L. D., Yang, P., and Vonder Haar T. H., 2008. Optical properties of a vertically inhomogeneous mid-latitude mid-level mixed-phase altocumulus in the infrared region. Atmos. Res., 88, 234-242.

Poore, K. D., Wang, J. H., Rossow, W. B., 1995. Cloud layer thicknesses from a combination of surface and upper-air observations. Journal of Climate, 8(3):550-568. 
Slingo, J. M., 1980. A cloud parameterization scheme derived from GATE data for use with a numerical model. Quarterly Journal of the Royal Meteorology Society, 106(450):747-770.

Sundqvist, H., 1978. A parameterization scheme for nonconvective condensation including prediction of cloud water content. Quarterly Journal of the Royal Meteorology Society, 1978, 104(441) : 677-690.

Tisler, P., and Savijärvi, H., 2002. On the parameterization of precipitation in warm clouds. Atmospheric Research, 63, 163176.

Wang, J. H., Rossow, W. B., 1995: Determination of cloud vertical structure from upper-air observations. Journal of Applied Meteorology, 34(10):2243-2258.

Zhao, Z., and Lei, H. C., 2014. Aircraft observations of liquid and ice in midlatitude mixed-phase clouds. Adv. Atmos. Sci., 31(3), 604-610. Doi: 10.1007/s00376-013-3083-2. 